Gut, 1978, 19, 267-272

\title{
Vitamin D-3 intestinal absorption in vivo: influence of fatty acids, bile salts, and perfusate $\mathrm{pH}$ on absorption
}

\author{
D. HOLLANDER, ${ }^{1}$ K. S. MURALIDHARA, AND ALICIA ZIMMERMAN \\ From the Division of Gastroenterology, Wayne State University and Harper Hospital, Detroit, \\ Michigan 48201, USA
}

SUMMARY Intestinal absorption of vitamin D-3 in physiological concentrations was studied in the live unanaesthetised rat. In both the jejunum and the ileum a linear relationship was found between the absorption rate of the vitamin and its intraluminal concentration. Increasing the sodium taurocholate concentration in the perfusate above $5 \mathrm{mM}$ did not change ileal absorption rate but did decrease jejunal absorption rate. The vitamin's rate of absorption was raised by increases in either the hydrogen ion concentration or the perfusate's flow rate. Addition of $2.5 \mathrm{mM}$ fatty acids of varying chain length and degrees of saturation resulted in a decrease in the rate of vitamin D-3 absorption. These experiments indicate that vitamin D-3 absorption in vivo is mediated by passive diffusion. The rate of absorption of the vitamin is influenced by the composition of the perfusate and the thickness of the unstirred layer.

Vitamin D is a lipid-soluble micronutrient which plays a pivotal role in the regulation of calcium absorption by the small bowel and calcium metabolism in bone. Everted rat gut sacs have been used to investigate the kinetics of the gastrointestinal tract's initial uptake of vitamin D-3 which was found to be absorbed by a nonsaturable passive diffusion process without requirements for energy or carrier mediation (Hollander, 1976). Absorption experiments which utilise everted gut sacs in vitro have definite technical limitations and the conclusions that are drawn from these experiments should be interpreted with caution (Smyth, 1974). The purpose of the present series of experiments was to study in vivo the absorption of physiological concentrations of vitamin D-3 in the restrained unanaesthetised rat. Proximal jejunal and distal ileal small intestinal loops were perfused and the absorption of vitamin D-3 was studied by varying the perfusate's flow rate, $\mathrm{pH}$, and concentrations of either the vitamin or bile salts and by adding fatty acids to the perfusate.

\footnotetext{
${ }^{1}$ Address for correspondence and reprint requests: Dr Daniel Hollander, Department of Medicine, Scott Hall of Basic Medical Sciences, 540 E. Canfield, Detroit, Michigan 48201, USA.
}

Received for publication 2 November 1977

\section{Methods}

MATERIA LS

${ }^{3} \mathrm{H}$ labelled-1,2, vitamin $\mathrm{D}-3(1.0 \mathrm{Ci} / \mathrm{mmol})$ was purchased from New England Nuclear, Boston, MA. Nonradioactive vitamin D-3 was purchased from Nutritional Biochemicals Corporation, Cleveland, $\mathrm{OH}$. The purity of the compounds was ascertained by thin layer chromatography on silica gel-G with chloroform (Hollander et al., 1971). The vitamin was not used if it contained more than $5 \%$ impurities. Mono-oleate and butyric, octanoic, oleic, and linoleic acids (Sigma Chemical Co., St. Louis, MO) were more than $97 \%$ pure when purchased. Thin layer chromatography (Gregg, 1966) revealed that purified sodium taurocholate (K \& K Laboratories, Plainview, NY) had less than $5 \%$ impurities, which consisted primarily of cholic acid. The standard intestinal perfusate was a micellar solution consisting of a Krebs phosphate buffer at pH 7.4 (Umbreit et al., 1972) and sodium taurocholate, fatty acids, mono-oleate, and vitamin D-3 at concentrations as specified. Micelles were produced by sonication for five minutes at 60 watts of power (Artek 150, Artek Corporation, Farmingdale, NY). Vitamin D-3 which had been dissolved in hexane, was placed in a glass homogeniser, the solvent was evaporated with nitrogen gas, 
and the perfusate solution was added to the homogeniser and mixed with the vitamin. The resultant micellar solution remained optically clear for 24 hours at $20^{\circ} \mathrm{C}$. In order to test the distribution of radioactive vitamin D-3 between the micellar and free monomeric forms of the vitamin, the final perfusate was passed through a UM-2 filter (Amicon Corporation, Lexington, MA). As less than $3 \%$ of the total radioactivity passed through the filter it was concluded that most of the vitamin was solubilised within the micellar particles. The final osmolality (Hendry, 1961) of the perfusate varied between 290 and $310 \mathrm{~m} 0 \mathrm{sm} / \mathrm{l}$. At the completion of experiments the $\mathrm{pH}$ of the perfusate varied from $7 \cdot 21-7 \cdot 34$. All work was performed in a partially darkened room in order to minimise exposure of the vitamin to ultra-violet radiation, which can change the vitamin's structure (Morton, 1970).

\section{PROCEDURE}

Male Sprague-Dawley rats weighing $180-225 \mathrm{~g}$ were fed regular chow (Check-R-Board, Novi, MI) and tap water ad libitum and were not fasted before experimentation. The animal was anaesthetised with ether and its abdomen was opened by a midline incision. Two polyethylene catheters $(6 \mathrm{~mm}$ O.D.) were used to isolate a $10-\mathrm{cm}$ proximal jejunal segment with the inflow catheter placed $2 \mathrm{~cm}$ distally to the entry site of the common bile duct. A distal ileal $10-\mathrm{cm}$ segment was similarly isolated with the outflow catheter being placed $2 \mathrm{~cm}$ proximally to the ileocaecal valve. The intestinal segments were flushed with Krebs phosphate buffer which was followed by air infusion in order to remove all residual contents. The intestinal loops were replaced into the peritoneal cavity, and the abdomen was closed. The animal was allowed to awaken and was placed in a restraint cage. The catheters from each intestinal segment were connected to separate reservoirs. Totally occlusive roller pumps (Buchler Instruments, Fort Lee, NJ) controlled the flow rate of perfusate from the reservoirs into the inflow catheters. The outflow catheters drained the perfusate from the intestinal segments to the reservoirs by gravity. The reservoirs and tubing were immersed in a constant temperature bath maintained at $38^{\circ} \mathrm{C}$. The animal's body temperature was monitored by a rectal thermister probe which was connected to a thermostatic temperature controller (Thermistemp Model 74, Yellow Springs Instruments, Yellow Springs, $\mathrm{OH}$ ) set to maintain the animal's body temperature at $38^{\circ} \mathrm{C}$ by intermittently activating a forced air heating device. Each reservoir was filled with $10 \mathrm{ml}$ of perfusate solution which was circulated at $0.5 \mathrm{ml} / \mathrm{min}$ unless indicated otherwise. The initial specific activity of the vitamin was calculated by measuring the radioactive counts of triplicate aliquots of the perfusate which contained known concentrations of the vitamin. After an initial 30minute equilibration period, 50-microlitre aliquots were removed from the perfusate every five minutes for 25 minutes and the rate of absorption was calculated by determining the rate of vitamin D-3 disappearance from the perfusate. At the end of perfusion the animals were killed by an overdose of ether. The perfused segments were carefully separated from their mesentery and suspended with a $10 \mathrm{~g}$ weight attached to their most dependent portion in order to provide a constant degree of stretching of the segments. After 24 hours of drying at $20^{\circ} \mathrm{C}$, the length of each segment was measured and the absorption rate of vitamin D-3 was expressed as a function of intestinal length. Net fluid shifts in the perfused segments were assessed in preliminary experiments by adding a nonabsorbable indicator, ${ }^{14} \mathrm{C}$ inulin (Miller and Schedl, 1970), to the perfusate, which did not contain radioactive vitamin D-3. Less than $5 \%$ net fluid absorption was found to take place during the 55 minutes of perfusion. Therefore, in this communication, no correction for fluid shifts was done.

\section{Radioactivity determinations}

The aliquots of intestinal perfusate were placed directly into scintillation counting vials which contained a dioxane based scintillation solution (Hollander and Truscott, 1974). The radioactivity was measured in a Beckman LS 250 liquid scintillation counter with automatic quench calibration at ambient temperature. Counts were carried to a maximal counting error of $1 \%$.

\section{Statistical calculations}

The data were analysed by the use of Student's $t$ test (Kramer, 1966), regression analysis (Draper and Smith, 1966), and analysis of variance (F-test) (Sokal and Rohlf, 1969).

\section{Results}

\section{ABSORPTION KINETICS}

The rate of vitamin D-3 absorption was tested at perfusate concentrations of 14-600 nM. Individual experiments at each concentration were analysed by a linear regression plot of absorption versus time with the value of the slope taken as the mean rate of absorption. Experiments were rejected if analysis of the slope resulted in $r<0.95$ and $P>0.05$ (Draper and Smith, 1966). Absorption rate of vitamin D-3 remained linear with its perfusate concentration in the present studies (Figure). Analysis of variance (Sokal and Rohlf, 1969) revealed no differences 
between the rates of vitamin D-3 absorption by the proximal and distal intestinal segments.

INFLUENCE OF TAUROCHOLATE CONCENTRATION ON VITAMIN D-3 ABSORPTION

Sodium taurocholate's concentration in the perfusate was varied from 5-15 mM. Experiments with sodium taurocholate concentrations below $5 \mathrm{mM}$ were not done because vitamin D-3 precipitates out of the solution at sodium taurocholate concentrations close to or below the critical micellar concentration of $3.2 \mathrm{mM}$ (Carey and Small, 1970). Proximal intestinal absorption of the vitamin was found to decrease as the concentration of sodium taurocholate was increased from 5 to $15 \mathrm{mM}$. No parallel changes in the absorption rate of vitamin D-3 by the distal small bowel were noted (Table 1).

Table 1 Effect of bile salt concentration on vitamin $D-3$ absorption in vivo

\begin{tabular}{|c|c|c|c|c|c|}
\hline \multirow{2}{*}{$\begin{array}{l}\text { Taurocholate } \\
\text { concentrations } \\
(m M)\end{array}$} & \multirow[t]{2}{*}{$\begin{array}{l}\text { Animals } \\
\text { (no.) }\end{array}$} & \multicolumn{4}{|c|}{$\begin{array}{l}\text { Absorption } \\
(\mathrm{pmol} / \mathrm{min} / 10 \mathrm{~cm})\end{array}$} \\
\hline & & Proximal & $P$ value & Distal & $P$ value \\
\hline $\begin{array}{r}5 \\
10 \\
15\end{array}$ & $\begin{array}{l}8 \\
6 \\
3\end{array}$ & $\begin{array}{l}67.1 \pm 2.3 \\
55.5 \pm 2.6 \\
52.2 \pm 1.9\end{array}$ & $\begin{array}{l}<0.01 \\
<0.01\end{array}$ & $\begin{array}{l}57.9 \pm 1.8 \\
57.1 \pm 1.4 \\
56.9 \pm 2.3\end{array}$ & $\begin{array}{l}>0.05 \\
>0.05\end{array}$ \\
\hline
\end{tabular}

Values for absorption represent the mean $\pm \mathrm{SE}$ of five experimental observations per animal. The perfusate consisted of the Krebs phosphate buffer, $\mathrm{pH} \mathrm{7 \cdot 4,500} \mathrm{nM} \mathrm{vitamin} \mathrm{D-3,} \mathrm{and} \mathrm{sodium} \mathrm{taurocholate.}$ The data were analysed statistically by comparing the absorption rate at 10 and $15 \mathrm{mM}$ taurocholate concentrations with the rates observed at $5 \mathrm{mM}$ taurocholate concentration.

INFLUENCE OF INTRALUMINAL PH ON

VITAMIN D-3 ABSORPTION

The $\mathrm{pH}$ of the perfusate was varied from $5 \cdot 3$ to $8 \cdot 3$ by changing the relative concentrations of the monobasic and dibasic phosphate in the Krebs solution (Umbreit et al., 1972). Increasing the hydrogen ion concentration in the perfusate caused a parallel increase in the absorption rate of vitamin D-3 by both the proximal and distal intestinal segments (Table 2).

\section{INFLUENCE OF FATTY ACIDS ON VITAMIN}

D-3 ABSORPTION

In the next series of experiments the absorption rate of vitamin D-3 in the presence of fatty acids was compared to the baseline absorption rate of the vitamin in the presence of $10 \mathrm{mM}$ sodium taurocholate only. The separate additions of the short chain saturated fatty acid, butyric (C4:0), the medium chain saturated fatty acid, octanoic $(\mathrm{C8}: 0)$, and the unsaturated long chain fatty acids, oleic
Table 2 Effect of intestinal perfusate $\mathrm{pH}$ on vitamin $D-3$ absorption in vivo

\begin{tabular}{llllll}
\hline$p H$ & $\begin{array}{l}\text { Animals } \\
\text { (no.) }\end{array}$ & $\begin{array}{l}\text { Absorption } \\
\text { (pmol/min/10 cm) }\end{array}$ & \\
\cline { 3 - 6 } & & Proximal & P value & Distal & P value \\
\hline 5.3 & 3 & $47.0 \pm 1.5-$ & $61.6 \pm 2.6$ & - \\
7.4 & 4 & $45.4 \pm 1.3<0.05$ & $53.2 \pm 2.8$ & $<0.01$ \\
8.3 & 3 & $28.0 \pm 0.3<0.01$ & $22.9 \pm 0.7$ & $<0.01$ \\
\hline
\end{tabular}

Mean \pm SE values of absorption derived from five observations per animal. The perfusate consisted of phosphate buffer, $500 \mathrm{nM}$ vitamin D-3, $10 \mathrm{mM}$ sodium taurocholate, $2.5 \mathrm{mM}$ oleic acid, and $2.5 \mathrm{mM}$ mono-oleate. Statistical analysis of the data was performed by comparing the absorption rate at each hydrogen ion concentration to the rate observed at the next lower pH using Student's $t$ test and analysis of variance.

(C18:1) and linoleic (C18:2), caused a significant decrease in the absorption rate of vitamin D-3 by both proximal and distal small bowel segments (Table 3).

\section{EFFECT OF PERFUSION RATE ON VITAMIN D-3 ABSORPTION}

As the perfusion rate was increased in a stepwise fashion from 0.5 to $10 \mathrm{ml} / \mathrm{min}$ both proximal and distal small bowel segments showed a significant increase in their rate of vitamin D-3 absorption (Table 4).

Table 3 Effect of fatty acid addition on vitamin $D-3$ absorption in vivo

\begin{tabular}{|c|c|c|c|c|c|}
\hline \multirow[t]{2}{*}{$\begin{array}{l}\text { Fatty } \\
\text { acid }\end{array}$} & \multirow[t]{2}{*}{$\begin{array}{l}\text { Animals } \\
\text { (no.) }\end{array}$} & \multicolumn{4}{|c|}{$\begin{array}{l}\text { Absorption } \\
(\text { pmol } / \min / 10 \mathrm{~cm})\end{array}$} \\
\hline & & Proximal & $P$ value & Distal & $P$ value \\
\hline $\begin{array}{l}\text { None } \\
\text { Butyric } \\
\text { Octanoic } \\
\text { Oleic } \\
\text { Linoleic }\end{array}$ & $\begin{array}{l}6 \\
7 \\
6 \\
9 \\
6\end{array}$ & $\begin{array}{l}55.5 \pm 2.6 \\
52.7 \pm 2.2 \\
41.2 \pm 2.3 \\
41.8 \pm 1.1 \\
40.5 \pm 1.7\end{array}$ & $\begin{array}{l}<0.05 \\
<0.01 \\
<0.01 \\
<0.01\end{array}$ & $\begin{array}{l}57.1 \pm 1.4 \\
53.2 \pm 4.7 \\
47.9 \pm 3.8 \\
39.6 \pm 1.6 \\
37.2 \pm 1.4\end{array}$ & $\begin{array}{l}-<0.05 \\
<0.01 \\
<0.01 \\
<0.01\end{array}$ \\
\hline
\end{tabular}

Mean \pm SE absorption rate based on five experimental observations per animal. The perfusate contained $500 \mathrm{nM}$ vitamin $\mathrm{D}-3$, and $10 \mathrm{mM}$ sodium taurocholate in the phosphate buffer with $2.5 \mathrm{mM}$ amounts of the fatty acids. Absorption rate of the vitamin in the presence of fatty acids was compared to absorption rate of the vitamin in the presence of sodium taurocholate only using Student's $t$ test and analysis of variance.

\section{Discussion}

The linear relationship between vitamin D-3 absorption and its concentration in the perfusate (Figure) supports the hypothesis derived from in vitro experiments that absorption of vitamin D-3 is mediated by a passive, nonsaturable diffusion mechanism without evidence for energy dependence or carrier mediation (Hollander, 1976).

In the present series of experiments, the highest 
Table 4 Effect of intestinal perfusion rate on vitamin $D-3$ absorption in vivo

\begin{tabular}{llllll}
\hline $\begin{array}{l}\text { Perfusion } \\
\text { rate } \\
(\mathrm{ml} / \mathrm{min})\end{array}$ & $\begin{array}{l}\text { Animals } \\
(\text { no. })\end{array}$ & $\begin{array}{l}\text { Absorption } \\
\text { (pmol/min/10 cm) }\end{array}$ & & \\
\cline { 3 - 6 } & & Proximal & P value & Distal & P value \\
& & & & & \\
\hline 0.5 & 4 & $45.4 \pm 1.3-$ & $53.2 \pm 2.8$ & - \\
2.5 & 3 & $50.5 \pm 2.4$ & $<0.01$ & $67.0 \pm 2.6$ & $<0.01$ \\
10.0 & 3 & $56.7 \pm 2.8<0.01$ & $88.9 \pm 3.1$ & $<0.01$ \\
\hline
\end{tabular}

The perfusate consisted of phosphate buffer, $500 \mathrm{nM}$ vitamin D-3, $10 \mathrm{mM}$ sodium taurocholate, $2.5 \mathrm{mM}$ oleic acid, and $2.5 \mathrm{mM}$ monooleate. Absorption at each flow rate was compared statistically to the absorption rate at the next lower flow rate using Student's $t$ test and analysis of variance.

rate of vitamin D-3 absorption by the proximal jejunum was observed when the perfusate's sodium taurocholate concentration was at $5 \mathrm{mM}$. As the concentration of sodium taurocholate was increased to 10 or $15 \mathrm{mM}$ the proximal jejunum showed a progressive decrease $(P<0.01)$ in its rate of vitamin D-3 absorption (Table 1). The most plausible explanation for these observations is that higher bile salt concentrations cause greater solubilisation within the micelle and a shift from the monomeric to the micellar form of the vitamin. Since lipids such as vitamin D-3 penetrate the absorptive cell membrane as monomers rather than micellar particles (Simmonds, 1974), the influence of higher sodium taurocholate concentrations would be to decrease the vitamin's rate of absorption. Why the distal ileum's response to higher sodium taurocholate concentrations is not similar to the jejunum's is not clear. Perhaps, the distal ileum - the site of the small bowel's most rapid and active absorption of sodium taurocholate-absorbs the compound sufficiently rapidly to minimise the initial differences in its concentration in the perfusate after the first 30 minutes of equilibration. Therefore, the influence of the higher bile salt concentrations on the distal ileum and its absorption of vitamin D-3 would be less than their influence on the jejunum, which is not the site of rapid, active absorption of sodium taurocholate.

Increasing the hydrogen ion concentration in the perfusate raised the rate of absorption of vitamin D-3 by both the proximal and distal small intestinal segments (Table 2). The influence of the hydrogen ion concentration upon the micelle and the absorptive cell membrane, rather than its influence on the solubility of sodium taurocholate or vitamin D-3, probably accounts for the changes in vitamin D-3 absorption. In this series of experiments the alteration in the hydrogen ion concentrations ( $\mathrm{pH} 5.3$ to $8 \cdot 3$ ) are unlikely to have influenced the aqueous solubility of vitamin D-3, which is negligible, or

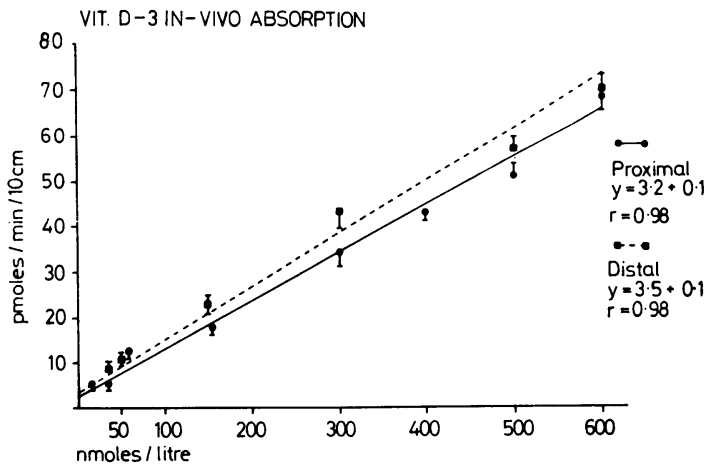

Figure Vitamin D-3 absorption at increasing perfusate concentrations of the compounds. Each point represents mean $\pm S E$ absorption rate from three to six animals with five observations per animal. The perfusate solution contained $10 \mathrm{mM}$ sodium taurocholate, $2.5 \mathrm{mM}$ oleic acid, and 2.5 mono-oleate.

the solubility of sodium taurocholate, which has a pKa of 1.8 (Carey and Small, 1970). On the other hand, varying the hydrogen ion concentration could cause changes in the surface charge of the micelle (Carey and Small, 1970) and the absorptive cell membrane (Schultz, 1974), both of which are negatively charged. An increase in the hydrogen ion concentration in the perfusate would reduce the negative charge of both the micelle and the luminal cell membrane and, hence, would decrease the resistance to diffusion of the micelles (Kruyt, 1952) towards the cell membrane. The intraluminal hydrogen ion concentration has been found to influence similarly the rate of absorption of another insoluble, non-swelling amphiphile, vitamin K-1 (Hollander et al., 1977). As vitamin K-1 and vitamin D-3 have different chemical structures but were similarly affected by variations in the hydrogen ion concentration, the $\mathrm{pH}$-induced changes in vitamin D-3 absorption are less likely to be caused by hydrogen ion interactions with the vitamin itself than by changes in the micellar and membrane charges themselves.

The addition of fatty acids to the infusate decreased the rate of vitamin D-3 absorption (Table 3). The mechanism responsible for the effect of short and medium chain fatty acids on vitamin D-3 uptake is not apparent. Butyric and octanoic acids would not be expected to alter the structure of the micelle itself as both fatty acids are water soluble and do not require micellar formation for their absorption (Jackson, 1974). Unlike long chain fatty acids and vitamin D-3, the short and medium chain fatty acids are transported out of the intestine into the portal circulation rather than into the lymphatic 
circulation (Bloom et al., 1951). Therefore, these fatty acids would not interact with vitamin D-3 at its exit out of the enterocyte or its entry into the vascular or lymphatic circulation. The site of interaction between the long chain fatty acids and vitamin D-3 is probably the micellar structure itself. The long chain oleic and linoleic acids are known to require micellar solubilisation for absorption. When added to bile salt solutions, they expand and increase the micellar size (Carey and Small, 1970). Hence, it is likely that the long chain fatty acids hinder vitamin D-3 absorption by causing enlargement of the micellar particles, thereby slowing their diffusion rate towards the absorptive cell membrane. In vivo studies of vitamins $\mathrm{K}-1$ and A-1 absorption also showed a decrease in their absorptive rate when linoleic acid was added to the intestinal perfusate (Hollander et al., 1977; Hollander and Muralidhara, 1977).

Thompson et al. (1969) found that vitamin D-3 removal rate from the luminal perfusate did not change when $9.6 \mathrm{mM}$ linoleic acid and $4.8 \mathrm{mM}$ mono-oleate were added to a $20 \mathrm{mM}$ sodium taurocholate solution. However, the small intestinal wall contained less vitamin D-3 at the conclusion of the experiments when the luminal perfusate did contain linoleic acid and mono-oleate. The discrepancies between their experimental findings and ours may be due to differences in the composition of the luminal perfusate. Their perfusate contained twice the amount of sodium taurocholate and six times more lipid than the perfusate used in the present experiments. Sodium taurocholate in the concentrations used in their experiments $(20 \mathrm{mM})$ has been demonstrated to inhibit water transport by the rat jejunum in vivo (Saunders, 1975) and to increase extrusion of fatty acids into the lymph (Clark et al., 1969). Thus, the differences in the bile acid concentration and fatty acid concentrations in the perfusate may have caused the discrepancy in the absorption rate of vitamin D-3 between the present experiments and the experiments reported by Thompson et al. (1969).

The unstirred water layer, a known barrier to lipid diffusion, can limit the absorptive rate of a lipid if the absorptive lipid's diffusion through the cell membrane is faster than its diffusion through the unstirred layer itself (Westergaard and Dietschy, 1974). In order to determine the influence of the thickness of the unstirred water layer on the absorption rate of vitamin D-3 in vivo, the thickness of the unstirred water layer was diminished progressively by increasing the perfusate flow rate (Lewis and Fordtran, 1975) from $0.5 \mathrm{ml}$ to $10 \mathrm{ml} / \mathrm{min}$ (Table 4). As the rate of perfusion was increased a progressive increase in the absorption rate of vitamin D-3 by both the proximal and distal small bowel was noted (Table 4). These experiments indicate that the unstirred water layer is a rate-limiting step in the absorptive pathway of vitamin D-3.

The concepts which are derived from these experiments broaden our understanding of the absorptive process of vitamin D-3 in particular and of lipid-soluble compounds in general. As vitamin D-3 and cholesterol are similar structurally (Fraser and Kodicek, 1968), some of the information gained from the present studies may be relevant to cholesterol absorption mechanisms as well.

These studies were supported by grant AM 17607 from the National Institute of Arthritis, Metabolism, and Digestive Diseases; The Skillman Foundation of Detroit, Michigan; and the Harper Hospital Research and Education Medical Staff Fund. Careful review of the manuscript by Dr P. A. Hollander and the secretarial assistance of Miss Barbara Glispin are gratefully acknowledged.

\section{References}

Bloom, B., Chaikoff, I. L., and Reinhardt, W. O. (1951). Intestinal lymph as pathway for transport of absorbed fatty acids of different chain lengths. American Journal of Physiology, 166, 451-455.

Carey, M. C., and Small, D. M. (1970). The characteristics of mixed micellar solutions with particular reference to bile. American Journal of Medicine, 49, 590-608.

Clark, M. L., Lanz, H. C., and Senior, J. R. (1969). Bile salt regulation of fatty acid absorption and esterification in rat everted jejunal sacs in vitro and into thoracic duct lymph in vivo. Journal of Clinical Investigation, 48, 1587-1599.

Draper, N. R., and Smith, H. (1966). Applied Regression Analysis, pp. 1-42. Wiley: New York.

Fraser, D. R., and Kodicek, E. (1968). Conformational similarities of vitamin $\mathbf{D}$ and cholesterol as enzyme substrates. Nature, 220, 1031-1032.

Gregg, J. A. (1966). New solvent systems for thin-layer chromatography of bile acids. Journal of Lipid Research, 7, 579-581.

Hendry, E. B. (1961). Osmolarity of human serum and of chemical solutions of biologic importance. Clinical Chemistry, 7, 156-164.

Hollander, D. (1976). Mechanism and site of small intestinal uptake of vitamin $D_{-3}$ in pharmacological concentrations. American Journal of Clinical Nutrition, 29, 970-975.

Hollander D., and Muralidhara, K. S. (1977). Vitamin A-1 intestinal absorption in vivo: influence of luminal factors on transport. American Journal of Physiology, 232, E471E477.

Hollander, D., Rim, E., and Muralidhara, K. S. (1977). Vitamin $\mathrm{K}-1$ intestinal absorption in vivo: influence of luminal contents on transport. American Journal of Physiology, 232, E69-E74.

Hollander, D., Rosenstreich, S. J., and Volwiler, W. (1971). Role of the duodenum in vitamin $\mathbf{D}_{3}$ absorption in man. American Journal of Digestive Diseases, 16, 145-149.

Hollander, D., and Truscott, T. C. (1974). Mechanism and site of vitamin K-3 small intestinal transport. American Journal of Physiology, 226, 1516-1522.

Jackson, M. J. (1974). Transport of short chain fatty acids. In Intestinal Absorption, Vol. 2 (Biomembranes, Vol. 4B), 
pp. 637-709. Edited by D. H. Smyth. Plenum Press: London.

Kramer, D. Y. (1966). Approximation to the cumulative T-distribution. Technometrics, 8, 358-359.

Kruyt, H. R. (1952). Colloid Science, p. 144. Elsevier: New York.

Lewis, L. D., and Fordtran, J. S. (1975). Effect of perfusion rate on absorption, surface area, unstirred water layer thickness, permeability, and intraluminal pressure in the rat ileum in vivo. Gastroenterology, 68, 1509-1516.

Miller, D. L., and Schedl, H. P. (1970). Total recovery studies of nonabsorbable indicators in the rat small intestine. Gastroenterology, 58, 40-46.

Morton, R. A. (1970). Chemical structure and physical properties. I. Sterols, provitamins D and vitamins D. In Fat Soluble Vitamins (International Encyclopedia of Food and Nutrition, Vol. 9), pp. 27-37. Edited by R. A. Morton. Pergamon Press: Oxford.

Saunders, D. R. (1975). Regional differences in the effect of bile salts on absorption by rat small intestine in vivo. Journal of Physiology, 250, 373-383.

Schultz, S. G. (1974). Principles of electrophysiology and their application to epithelial tissues. In Gastrointestinal
Physiology, pp. 68-103. Edited by E. D. Jacobson, and L. L. Shanbour. University Park Press: Baltimore.

Simmonds, W. J. (1974). Absorption of lipids. In Gastrointestinal Physiology, pp. 343-376. Edited by E. D. Jacobson, and L. L. Shanbour. University Park Press: Baltimore.

Smyth, D. H. (1974). Methods of studying intestinal absortion. In Intestinal Absorption,Vol. 1 (Biomembranes, Vol. 4A), pp. 241-283. Edited by D. H. Smyth. Plenum Press: London.

Sokal, R. A., and Rohlf, R. J. (1969). Biometry, pp. 448-468. Freeman: San Francisco.

Thompson, G. R., Ockner, R. K., and Isselbacher, K. J. (1969). Effect of mixed micellar lipid on the absorption of cholesterol and vitamin $\mathrm{D}_{8}$ into lymph. Journal of Clinical Investigation, 48, 87-95.

Umbreit, W. W., Burris, R. H., and Stauffer, J. F. (1972). Manometric and Biochemical Techniques, 5th ed., p. 146. Burgess: Minneapolis.

Westergaard, H., and Dietschy, J. M. (1974). Delineation of the dimensions and permeability characteristics of the two major diffusion barriers to passive mucosal uptake in the rabbit intestine. Journal of Clinical Investigation, 54, 718-732. 